\title{
"Shameless" Sedentarism: Individual Responsibility for Health?
}

 \\ ${ }^{1}$ Regional University of Blumenau, Blumenau, Brazil \\ ${ }^{2}$ Federal University of Viçosa, Viçosa, Brazil \\ Email: *marcos_bagrichevsky@yahoo.com.br
}

How to cite this paper: Bagrichevsky, M., \& dos Santos, D. S. (2018). "Shameless" Sedentarism: Individual Responsibility for Health? Psychology, 9, 760-772.

https://doi.org/10.4236/psych.2018.94048

Received: March 14, 2018

Accepted: April 21, 2018

Published: April 24, 2018

Copyright (c) 2018 by authors and Scientific Research Publishing Inc. This work is licensed under the Creative Commons Attribution International License (CC BY 4.0).

http://creativecommons.org/licenses/by/4.0/

\begin{abstract}
The text critically addresses the polarity between discourses on sedentary and healthy lifestyles, contextualized by new technological resources for searching and disseminating information about health. The argument is that contemporaneous technoscientific rationality has created an "economy of truths" that, with the perspective of leading to safe lifestyles, have been prescribing a normative set of self-discipline ideals which generates anxiety and distress. In the hegemonic production of these regimes, sedentary lifestyle presents itself as a health risk, equivalent to moral failure and an unacceptable lack of self care. We highlight that the abundance of discourses about lifestyles and risk, seen as biopolitical devices imbricated in the processes of communication in health matters, deserves attention for their ethical and political implications. The display of lifestyles associated with the consumption and the production of narratives that perversely influence our culture has taken us far away from a socially possible notion of health. Finally, the regulatory essence of such symbolic references in building knowledge systems that have been (re)defining what means to be healthy, normal, unhealthy is discussed.
\end{abstract}

\section{Keywords}

Sedentary Lifestyle, Healthy Lifestyle, Discourses on Risk, Biopolitics, Information on Health

\section{Introduction}

Discourses associate certain human behaviors to the so-called health risk factors rule over scientific productions in the biomedical field for some time now (Lupton, 1995). Nevertheless, in the last few years the range of attitudes considered as unhealthy has increased in these studies, which in a certain way, have under- 
mined everyday life subjectivities (Castiel \& Alvarez-Dardet, 2007).

Sedentary lifestyle-a kind of postmodern metaphor used to designate indolence, laziness and an unacceptable lack of self-care-frequently appears in research as one of those behaviors that refer to moral failure (Buchanan, 2006) and seems to be self-explanatory among so many other serious health problems related to the population of unequal and underdeveloped countries, such as Brazil.

The arguments presented by epidemiological studies about the antinomy of "sedentary-healthy" lifestyles bring to light styles of thought engaged in establishing truth regimens (Lupton, 1999), of which developments and interests exceed the scientific field itself. When incorporated with investigations on mapping health risks, it is possible to note the increasing relevance of this type of categorization to the detriment of other issues that should be taken into consideration. In a certain way, this epistemological impoverishment has been criticized by analysts from both inside and outside the epidemiological field (Lupton, 1997; Krieger, 1999), due to the fact that the modern epidemiology is progressively getting far away from the collective sanitary issues it used to deal with in its historical origin, adopting more individualistic perspectives to investigate the phenomenon.

Assuming that the fight against sedentary lifestyle is really a plausible objective related to Public Health, how can it be done without stigmatizing people who are classified as sedentary? Would the "sedentary" category-legitimated in the studies based on criteria of minimum caloric expenditures per day on voluntary and/or recreational physical activity-be "applicable", for instance, to civil construction workers from underdeveloped countries whose daily hardwork schedule, invariably with no leisure time (due to poor financial conditions or physical fatigue resulting from exhaustive work) acts harmfully to their bodies?

If juxtaposed to the precepts which define sedentary lifestyle, should physical activity at work-which has led Brazilian rural workers who cut sugar cane to die at harvests (most of them, migrants from distant regions of the country) in exchange for very low compensation in the State of São Paulo, Brazil (Alessi \& Navarro, 1997)-be considered a health protection factor or a health risk factor?

From the point of view of social determinants about health, not only the classification is inappropriate, but also the recommendation of behavioral (lifestyle) changes is wrong, when inferred as a kind of cure in epidemiological investigations that advocate the relevance of the supposed problem. Boltanski's classic study (Boltanski, 1971) supports this argument when showing that decades ago the economic stratification of populations (distance between poor and rich people) was usually related to the socio-cultural valuation (symbolic and material) of the uses of the body and its archetypes. Therefore, according to this approach, the notion of a sedentary lifestyle would be legitimized from the epidemiological point of view, through a significant bias of social class.

The waiver to philosophical rigor in the analysis of some central concepts related to the institutionalization of health promotion practices, such as a seden- 
tary lifestyle, has been generating restricted notions of an individual isolated from their cultural context (Lupton, 1997) and their potential to interfere in public agendas. Such emphasis on individual action may promote autonomy concerning to form, although depoliticizing in essence.

Under this perspective, it seems prudent to relativize the superlative rhetoric which is commonly applied to everyday behaviors, taken as unhealthy or dangerous in epidemiological interpretations and shown by mass media (Lupton \& Chapman, 1995). There is a wide range of work that consider this strategy temerarious, since it became a moralizing imperative (Lupton, 1995; Martin, 2001; Buchanan, 2006; Campos et al., 2006) that generates significant repercussions on contemporaneous life, dictating subjective ways for us to behave, eat and relate to each other, interfering in the conformation of our beliefs and historically cultural values.

Ultimately, these discourses are responsible for an adverse effect that presents a persecutory dimension to individuals facing health proposals based on behavioral models composed of the healthy lifestyle idea and strategies that cause a preventive culpability for those who expose themselves to the technically pre-dimensioned risks (Castiel \& Alvarez-Dardet, 2007).

We are increasingly advised about our freedom to opt and choose how to conduct our health and our lives, through the management of information about studied, measured and denominated risks. The persuasive messages of this sanitary biopolitics are disseminated in the virtual boundaries that separate science, media and market, emerging in times marked by the concomitant increase of social inequalities and information flow (Poster, 1991), composing a new postmodern economic and cultural phenomenon: the moral aggravation of sedentary lifestyle as a contemporaneous sin.

It is, therefore, the rhetorical power coming from the idea of error or conduct deviation that leads to damage to yourself and others (e.g., the charge on health systems), that associated with sedentary lifestyle, enable us to explore some elements related to the core of this work, already shown by the title.

\section{Technoscientific Rationality and Anticipatory Discourses on Health Risks}

In order to examine the meanings constructed within this sanitary logic-subtle and deeply interwined into the discourses on risks, it is necessary to consider, at once, their relationship with the ruling emblematic perspective of the predominant biotechnoscientific rationality that produces homogenizing ideologies and politics (Lupton, 1999; Castiel \& Alvarez-Dardet, 2007), as well as the effects of the globalization processes which have made collective life fragile, insecure and susceptible to the commercialization of the body and health itself. According to Bauman (1995), these aspects have defined the conceptual basis of values for the human condition.

Currently, it is possible to note the increasing dissemination of prescriptive 
rules in line with (self) discipline and behavioral patterns to promote "good health", are not necessarily followed to the same extent by discussions about what that means.

In times of a voracious neoliberal capitalism it is important to remember that science and technology represent emblematic signs in globalized societies (Castells, 2000). This is because they have become powerful strategic forces, responsible for unleashing huge transformations in the health field, in the physical environment and in several macro and micro-political spheres of collective life.

For this and other reasons, social analysts-from inside and outside the field of health science-are concerned about the exponential growth of the discourse on prevention-anticipation of risks that feature prominently in many research areas, such as, genetic epidemiology and molecular biomedicines (Lewontin, 1993).

Different scholars defend (with their own arguments, disseminated by the mass media) ways and procedures to avoid risks to the individual's health. There are a lot of promises concerning the reduction of uncertainties and risks through efficient healing processes (therapies) on populational scales, gathered around the unconditional defense of a technicist discourse that, even though appears to be univocal, has revealed ambivalences (Welch et al., 2011).

In general, such promises do not consider the socio-political, cultural and economic influences stemming from complex phenomena. Actually, there is a broad dissemination of a number of simplistic solutions to complex issues, such as health care. Among this abundant production and exposure of offers to society, it is not hard to notice evidence of a reductionist orientation governed by ideological and market interests (Sfez, 1994; Bauman, 1995).

Different observers (Illich, 1982; Sfez, 1994; Castiel \& Alvarez-Dardet, 2007; Welch et al., 2011) highlight that supposed rhetorical guarantees projected by this preventive rationality do not necessarily generate peace, certainty, efficacy, or even present more adequate ways to deal with health issues in the context of everyday life. Those observers do not realize the number of particularities that constitute the contemporaneous man and they end up producing reductionist discourses that cause anxiety and distress (Lupton \& Chapman, 1995).

Such repercussions acquire a special meaning in the processes of health/disease/care, especially if we assume it as an expression of possible ways to manage (and even resist to) desires and expectations, presented to us nowadays, as unreachable needs in a contradictory world. For example, this paradox refers, on one hand, to the profusion of all types of stimulus directed to unlimited and mass consumption. While on the other hand, a substantial part of the population in the so-called "global village" remains poor and besides decent social politics (Bauman, 1995).

Thus, from these concrete environments of everyday life-spaces of socio-historical networks in which we are immersed- "singular truths" frequently arise, truths that are nontransferable or not very close to generalizing scientific propositions. 
Such singularities may be diluted or even annihilated by gaps (sometimes abyssal ones) between what is presumed to be the level of anticipatory discourses on risk, offered on a large scale, and what really happens for those whom these messages are directed (Lupton, 1993).

However, this critical examination we are highlighting does not invalidate or deny the need to take into consideration and to include epidemiological and clinical knowledge, besides innovative scientific practices in the different professional fields that act in Public Health, as their importance and notorious usefulness are acknowledged for a long time now. That would be incoherent.

Considering the presented argument, we aim to highlight that the essential grounds that govern what we call diagnosis-preventive discursive protocols (directed both to individuals or society more collectively) are insufficient, since their universal claims have been guiding hegemonic ways of thinking about and intervening in the processes of health/disease/care.

Such strategies may, undesirably and ambiguously, cause iatrogenic side effects in different perspectives, as shown by some studies (Illich, 1982; Lupton \& Chapman, 1995; Barreto, 2006; Welch et al., 2011). These discourses, in general, do not address the (many) unequal contexts of each population reality to which their basic precepts are widely spread. There is an extensive literature identifying these gaps and mismatches regarding such imposing standards (Lupton, 1993; Canclini, 1995; Campos et al., 2006).

It is important to mention that the expression diagnosis-preventive discursive protocols is understood here as rhetorical actions/techniques/strategies that, based on the technical-instrumental scientific rationality, have been trying to standardize a universal synthesis of biological and socio-cultural phenomenon, minimizing their different nuances (protocol) through generic descriptions of a given procedural context (diagnosis), in order to suggest "solving measures" that, in theory, would prevent or anticipate a certain problem (prevention).

Anticipatory discourses on health risks are included in this perspective. They are constituted and disseminated by different social actors and environments, forming a wide network of micro-decisions that produce ideologies (Lewontin, 1993; Castells, 2000), where the institutions, the subjects and their (inter)subjectivity stand, with several decision powers and interests. Discourses on health risks, targeting imagined receptors, are created exactly among this interactive ambivalence of unbalanced forces.

There is an assumption that the notion of risk has been replacing the idea of social norm as the predominant way to think about power over human action in the western culture (Petersen \& Lupton, 2000). The concept of risk prevails in this postmodern (and deeply unequal) society, where there is little margin of individual autonomy regarding (possible) choices of lifestyle. Through the molecularisation of mechanisms to control the individuals, these mechanisms became more appropriate to the relationships of powers and ways to organise current society, through its persuasive and permeable subtleties, lined, almost invisible 
(Deleuze, 1990).

The intention of these rhetorical recommendations to pursuade people to idealized lifestyles as healthy can only be really evaluated as soon as its assumptions become effective-when, where and if they do. Technoscientific sanitary discourses (Lupton, 1995; Lupton \& Chapman, 1995; Holmberg \& Parascandola, 2010; Welch et al., 2011), shaped by relationships of knowledge/power (Foucault, 1978) due to their relevance in the agenda of political issues, gain the power of symbolic references in the construction of identities and social relationships, knowledge systems and social values (Foucault, 1981; Fairclough, 1998).

Considering that such discourses constitute ways of thinking and acting that interfere on different areas of human life, it is necessary not only to locate them in the actual historical context-in order to carefully analyze their complex and influent logic in articulation-but also to investigate how different subjects move within these ways of production and circulation. It is also important to find out the reasons which make them legitimated, denied, remade or gain new meanings in the spaces they take place.

Discourses on health risks are normative constructs and are undoubtedly linked to different interests. They are formed, explicitly or not, from the aspired kind of society and the ways to reach it (Robertson, 2001).

Within these rhetorical politics, a type of redefinition of the sense of normality regarding the human condition is being legitimated, where diseases are reconceptualized as errors in our genetic code that need to be corrected in order to reactivate the health of the body and soul, individual and social and new dynamics of biopower are associated to the logic of consumption in the globalized capitalist market. From this view, it would not be necessary to find a pathological cause for the symptoms anymore; it would be enough to evaluate their distance from normal standard (i.e., assess risks).

The exhausting search for etiological descriptions of organic phenomenon-like the one operated by the Human Genome Project, among others (Sfez, 1994) - does not only aim to enlarge the understanding about the health/disease process of the population. It is also, by the same extent, initiates the truth about things (Foucault, 1981), dividing the world in two: the ones who know (the experts) and those who don't (the lay population). Within this economy of truth, the concept of risk arises as a category of "pre-disease", obviously subject to the experts' intervention (Phillips \& Ilcan, 2007).

Different authors (Sfez, 1994; Petersen \& Lupton, 2000; Martin, 2001; Robertson, 2001; Holmberg \& Parascandola, 2010) critically point out the clear profusion of discourses in risks with culpability in several institutional strategies to promote health for individuals, communities and for the planet. Despite the fact that these messages are still being studied, related to the prevention of sanitary damages, it is argued that it is not always possible to note significant effects in minimizing the problems they are supposed to solve.

Although it is praiseworthy to implement actions and ideas in order to mi- 
nimize emblematic issues in Public Health (e.g., diseases as tuberculosis, which [re]appear due to social-economic conditions of inequalities in marginal Latin America countries), several analysis have identified, within this trend, a conservative and illuminist belief, with a strong moralizing trait and narrow links with the market.

\section{The Crusade for the (De)Moralization of (Un)Healthy Behaviors}

More recently, some of the politics surrounding health in Brazil, situated within the boundaries of this neo-hygienist concept, have been proclaiming the idea of using/prescribing systematized practices of physical activity (PA) as alternatives to fight morbidity and mortality related to chronic-degenerative diseases, but, especially as discursive mechanisms to exorcise the modern man's contemporaneous sin: the sedentary lifestyle (Bagrichevsky et al., 2007). The arguments of this anti-sedentary lifestyle healthy crusade are mainly supported by the etiological theories of the lifestyle and by statistical results which comes from epidemiological researches.

In this context, the sense of corporal practices associated to cultural identities in groups and individuals, with the ludic dimension and pleasure that these practices may provide, is losing its place in contemporary life. It is also worthy to state that, under the current point of view of some government agendas, the inclusion of PA (programs) as a the action of public politics then arises as a "bitter medicine", but necessary, to fight the evils and damages that, as announced by official discourses, account for unacceptable expenses for public coffers. There is a clear attempt to establish a convincing argumentation that comes from reductionist and causal inferences, supported, a priori, by an economic logic that $\mathrm{cu}-$ riously, superposes and comes before the concerns with the health of the population (Jallinoja et al., 2010).

It seems worth mentioning here another exception. It is necessary to make clear that we are not denying the well-known benefits provided by PA to the body which is conducted with respect to individual limits and contexts. Far from that, the central issue claimed here is the expropriation of corporal cultural practices' values and meanings nowadays, which now fill the social imaginary of our collectivities, mixed with a perspective that is imposing, medicalizing, blaming and that promotes caloric expenditure as a way to avoid health risks (Lupton, 1995; Petersen, 2007).

In a clear attempt to strategically validate the notion of sedentary lifestyle as one of the many risk behaviors, universalizing it among us as an unquestionable scientific truth, a significant part of biomedical studies have disseminated the perception that the reduction of people's physical activity should be considered as one of these health damaging behaviors.

It is interesting to notice that not a long time after the Industrial Revolution, the term sedentary was used as an antonym for nomad (people or groups that 
would not settle down in one location, what was not interesting for the industrial revolution movement, once these people could not be framed by the new economic order of that time, being established with the appearance of western industrial city models). The meaning of such a word today may be considered as a neo-hygienist linguistic appropriation, with the purposes of blame. A sedentary person, according to this view, is someone responsible for neglecting his/her own physical appearance and health; someone that always feels guilty for not following the prescribed rigor of healthy behavior, including the practice of physical activity, is considered as individual proof of good principles.

Le Breton (2003) confirms that such interpretations are moral attributions of the society, which has proven to be incompetent in its anthropological function of orientating human existence, where collective limits and cultural values have lost their legitimacy and are becoming temporary. In this view, the author points out the contradictory emergence of practices associated to the adventure-risk and radical sports, with a logic that is contrary to the one categorizing the sedentary body as lazy and passive. Distinguished by the staunch character and moral righteousness, the (physically) "active" subject would exhibit a mark that proves his value with the act of voluntarily risking his own integrity and health, going through extreme bad weather conditions, at the expense of the body's organic limits and pain, in order to show the ability to face death without failing.

On the other hand, part of the extension of this problematic position that isolates the sedentary person in his/her own existential negativity results from the diffusion of messages in the media that suggest that health can be obtained from the consumption of all kinds of products (diet food, creams, equipments, drugs, etc.) and services (fitness centers, treatments and aesthetic surgeries, etc.) available in the market. An informative-advertising bombardment is used for this purpose, with psychological, affective and moral persuasive strategies. It is the way to show and talk about a body, another one, distinctively lived and invested, by a number of manners of control, incorporated by different rhythms of production and consumption, of pleasure and pain (Markula \& Pringle, 2006).

The exacerbation of self care at the level of individual/private health, the proliferation of a volatile ethic of the western beauty and corporal qualities, outlined by the contemporaneous aesthetical taste is becoming more and more a public imperative and, as a consequence, a central concern in the life of a growing increasing number of people (Markula \& Pringle, 2006; Petersen, 2007). The investment in individualism is one of the ethical-political topics that reoccur in discussions about what separates us from modernity.

It is important to remember that a lot of people have been subjecting themselves to the suffering and sacrifices because of this standard discourse in order to gain longevity, repair aesthetical imperfections, masking age signs on their bodies and ultimately, trying to prevent death (Castiel \& Alvarez-Dardet, 2007). Although in order to do so they have to invariably expose themselves, with no further explanations about the risks of going through severe health problems 
(and, in some cases, even die), in the attempts to change their bodies, in a routine motivated and naturalized by different media strategies, driven by aesthetic and fitness industries (Markula \& Pringle, 2006).

Clear examples of these iatrogenic ways to deal with the body and health (made public recently) are when young people become increasingly susceptible to the detrimental effects of massive use of anabolic steroids, appetite inhibitors and the higher number of clinical occurrences such as anaphylactic shock, comas and cardiac failures during liposuction surgeries, due to the increasing number of this type of intervention (Markula \& Pringle, 2006; Petersen, 2007).

However, we are not proposing a manicheist analysis about the decision of enjoying or not the freedom regarding the person's own health; instead, we want to highlight the need to reexamine the universal prescriptive standards, included in hegemonic discourses about sedentary lifestyles, PA and healthy lifestyles. It is essential to problematize where the discourses come from and their network of interests which, by being shown publically, become attractive references to certain groups of imagined receptors.

It is also important to consider that other socio-discursive references are in a certain way, marginalized or discarded by the mass media, since they could be more adequate alternatives for personal and collective choices regarding ways of living and dealing with the own health. Undoubtedly, this unfair game of tensions subjectively interferes in the decisions about what (and how much) we eat; whether we should smoke, have alcoholic beverages; do physical exercises, among other everyday practices. Thus, it is urgent to think about the kind of life that is being built by these alerts on dangers (risks) that supposedly, would ambush us in our habits and that could become real in a distance future.

However, it is well-known that such ethical boundaries have been bumping on movable basis in the contemporaneous globalized world. Lupton (1995) advises that the price paid for the eventual defense of a resistance posture before imperative health rules may be catastrophic, often leading to social stigmatization of people and to the fragility of identity bonds between peers in several spaces of everyday life: from relationships at work to those in the affective world.

\section{Final Considerations: Spread of Healthy Lifestyles as a Biopolitical Device}

Several works have shown concerns with the disciplinary guidelines of the principles of a healthy life (Markula \& Pringle 2006; Castiel \& Alvarez-Dardet 2007; Petersen 2007). Such orientation, motivated by an ideal of body constitution, proves to be more and more surrounded by moral based implications: in opposition to the shameless sedentary lifestyle is the virtuous option for a socially idealized healthy behavior.

Being healthy, nowadays, is no longer a symbolic path through which people would try to reach welfare; it became our existence's own purpose, a persecutory goal (Castiel \& Alvarez-Dardet 2007) desired no matter what. Overlapping this 
rhetorical dimension, expressions such as healthy lifestyle and sedentary lifestyle (risk behavior) frequently adopt the respective meanings of normal and pathological identities (Canguilhem, 1991), subordinating us more and more to these discursive practices (Foucault, 1977).

As Foucault (1978) suggests, our biological life is a political event, whose control has proved to be essential to the hegemonic relationships between the State and the people, since through the employment of power techniques over an individual body (creation of behavior rules and disciplines), it is possible to control the social body.

Analyzed from this perspective, strategies in health education and health promotion which emphasize behavior changes (Coveney, 1998; Jallinoja et al., 2010) may represent unique contributions to the employment of biopower, because they cover discipline and rules of conduct, which have the purpose of encouraging "good health" and interfering in personal choices, as they instruct on how to reach healthy lifestyles.

Contemporaneous society, traversed by digital information of immaterial inspiration (Castells, 2000), positions the biological features of our genetic inheritance (DNA) exactly in the intersection between the individual body and the social body (Lewontin, 1993), as a privileged target both of the biopolitics that converge to the human population and the specific technologies of subjective shaping.

These are analytical concerns that surround a broad range of research related to health (Lupton, 1995; Markula \& Pringle 2006; Petersen, 2007). Such a problematizing dimension may encourage promising ways of understanding a complex regulatory structure of scientific-rational actions which have: 1) instituted rhetorics, attitudes and strategies (also) in the sanitary field; 2) subsidized the formulation of public politics; and 3) propelled (in)directly the profitability of huge transnational conglomerates of the medical-industrial complex and the markets of cosmetics, fashion, fitness and entertainment, dealing with unimaginable amounts of money.

Despite of its prestige with the official instances of science and technology, the theme of informational biopolitics in health (Deleuze, 1990; Poster, 1991) deserves attention for its deep and worrying implications to human life in the beginning of this $21^{\text {st }}$ century.

These singularities still need to be explored and reinterpreted under the apparent polarity between the recommendation of healthy lifestyles and the demonization of sedentary lifestyle (and sedentary people) which was the major issue that motivated us to pose it as a relevant topic in the current text. Above all, we must take into account the social context that surrounds us, where an extremely fast dissemination of new discursive protocols and use of information in the field of health have been imposing renewable and changing technological models, such as the internet, which contents often present non-critical, banal forms of interpreting major events of our lives. 
The range and complexity of these issues, which involve a number of social spheres, demand the urgent revision of the epistemological, political and ethical foundations in use on communicational processes in Public Health. Considering this theme's relevance, researchers in the media have also been making efforts to put together a critical grammar of excess, spectacularization and fabrication of images and narratives that cross this field (Lupton \& Chapman, 1995; Castells, 2000).

Canclini (1995) reinforces this concern when he ironically declares that nowadays we find ourselves in the "society of the unknowledgable", characterized by the accumulation of useless, unimportant information which has been present in public communication, including when it comes to the sanitary field. Analysis of this kind suggest the need to reexamine the processes of construction and dissemination of fallacious promises, which perversely hit collective life and move us away from a daily life based on more humanized cultural health practices.

Strongly linked to these subjective productions, the aversion to the so-called health risk behaviors, among which is the sedentary lifestyle, builds itself more and more over the prevailing moral obligation associated with the controlling technoscientific expertise. This overview feeds the hyper vigilant and suspicious environment that dominates several levels and aspects of life nowadays (Van Loon, 2002).

Despite the higher number of widespread ideas in the media and information about ideal lifestyles, there are still getaway options when it comes to dealing with health, which may be more compatible with the references of our lives' histories, and in compliance with another ethos (Deleuze \& Guattari, 1987). Because, as we shall agree, there are as many possible ways of being healthy as there are of being human.

\section{Acknowledgements}

The authors wish to thank the National Council of Technological and Scientific Development (CNPq) and the Bahia State Foundation for the Support to Research (FAPESB) for the financial support to the researches.

\section{References}

Alessi, N. P., \& Navarro, V. L. (1997). Health and Work in Rural Areas: Sugar Cane Plantation Workers in Ribeirão Preto, São Paulo, Brazil. Reports in Public Health, 13, s111-s121.

Bagrichevsky, M., Estevao, A., \& Vasconcellos-Silva, P. R. (2007). Sedentarism, We and the (im)Possible World on the Context of Science. Journal of Public Health, 41, 862-864.

Barreto, M. L. (2006). Health Technologies and the Fine Balance between Risks and Benefits. Journal of Public Health, 40, 397-399.

Bauman, Z. (1995). Modernity and Ambivalence. Cambridge: Polity Press.

Boltanski, L. (1971). Les usages sociaux du corps. Les Annales, 1, 205-233. 
https://doi.org/10.3406/ahess.1971.422470

Buchanan, D. (2006). Moral Reasoning as a Model for Health Promotion. Social Science and Medicine, 63, 2715-2726. https://doi.org/10.1016/j.socscimed.2006.07.002

Campos, P., Saguy, A., Ernsberguer, P., Oliver, E., \& Gaesser, G. (2006). The Epidemiology of Overweight and Obesity: Public Health Crisis or Moral Panic? International Journal of Epidemiology, 35, 55-60. https://doi.org/10.1093/ije/dyi254

Canclini, N. G. (1995). Hybrid Cultures: Strategies for Entering and Leaving Modernity. Minneapolis: Uni Minnesota Press.

Canguilhem, G. (1991). The Normal and the Pathological. New York: Zone Books.

Castells, M. (2000). The Rise of the Network Society: The Age of Information-Economy, Society and Culture (Vol. 1). Oxford: Blackwell Publishers.

Castiel, L. D., \& Alvarez-Dardet, C. (2007). Persecutory Health. Journal of Public Health, 41, 461-466. https://doi.org/10.1590/S0034-89102007000300019

Coveney, J. (1998). The Government and Ethics of Promotion Health: The Importance of Michel Foucault. Health Education Research, 13, 459-468. https://doi.org/10.1093/her/13.3.459

Deleuze, G. (1990). Postscript on the Societies of Control. Pouparlets: Columbia University Press.

Deleuze, G., \& Guattari, F. (1987). The Thousand Plateaus: Capitalism and Schizophrenia. Minneapolis: Minnesota Press.

Fairclough, N. (1998). Discourse and Social Change. Cambridge: Polity Press.

Foucault, M. (1977). Discipline and Punish: The Birth of the Prison. New York: Random House.

Foucault, M. (1978). History of Sexuality I: The Will to Know. New York: Random House.

Foucault, M. (1981). The Order of Discourse. London: Routledge.

Holmberg, C., \& Parascandola, M. (2010). Individualised Risk Estimation and the Nature of Prevention. Health, Risk \& Society, 12, 441-452. https://doi.org/10.1080/13698575.2010.508835

Illich, I. (1982). Medical Nemesis: The Expropriation of Health. New York: Pantheon.

Jallinoja, P., Pajari, P., \& Absetz, P. (2010). Negotiated Pleasures in Health-Seeking Lifestyles of Participants of a Health Promoting Intervention. Health: An Interdisciplinary Journal for the Social Study of Health, Illness and Medicine, 14, 115-130. https://doi.org/10.1177/1363459309353292

Krieger, N. (1999). Questioning Epidemiology: Objectivity, Advocacy, and Socially Responsible Science. American Journal of Public Health, 89, 1151-1153. https://doi.org/10.2105/AJPH.89.8.1151

Le Breton, D. (2003). Anthropologie du corps et modernité. Paris: Presses Universitaires de France.

Lewontin, R. C. (1993). Biology as ideology: Doctrine of DNA. New York: Harper-Collins Publishers.

Lupton, D. (1993). Risk as Moral Danger: The Social and Political Functions of Risk Discourse in Public Health. International Journal of Health Services, 23, 425-435. https://doi.org/10.2190/16AY-E2GC-DFLD-51X2

Lupton, D. (1995). The Imperative of Health: Public Health and the Regulated Body. London: Sage. 
Lupton, D. (1997). Epidemiology as a Sociocultural Practice. Critical Public Health, 7, 28-37. https://doi.org/10.1080/09581599708409076

Lupton, D. (1999). Risk. London: Routledge.

Lupton, D., \& Chapman, S. (1995). A Healthy Lifestyle Might Be the Death of You: Discourses on Diet, Cholesterol Control and Heart Disease in the Press and among the Lay People. Sociology of Health and Illness, 17, 477-494.

https://doi.org/10.1111/1467-9566.ep10932547

Markula, P., \& Pringle, R. (2006). Foucault, Sport and Exercise. New York: Routledge.

Martin, M. W. (2001). Responsibility for Health and Blaming Victims. Journal of Medical Humanities, 22, 95-114. https://doi.org/10.1023/A:1009074811781

Petersen, A. (2007). The Body in Question. New York: Routledge.

Petersen, A., \& Lupton, D. (2000). The New Public Health: Health and Self in the Age of Risk. London: Sage.

Phillips, L., \& Ilcan, S. (2007). Responsible Expertise. Critique Anthropology, 27, 103-126. https://doi.org/10.1177/0308275X07073821

Poster, M. (1991). The Mode of Information: Poststructuralism and Context. Chicago, IL: Chicago University Press.

Robertson, A. (2001). Biotechnology, Political Rationality and Discourses on Health Risk. Health: An Interdisciplinary Journal for the Social Study of Health, Illness and Medicine, 59, 293-309. https://doi.org/10.1177/136345930100500302

Sfez, L. (1994). La sante parfaite: Critique d'une nouvelle utopie. Paris: Seuil.

Van Loon, J. (2002). Risk and Technological Culture: Towards a Sociology of Virulence. London: Routledge. https://doi.org/10.4324/9780203466384

Welch, H. G., Schwartz, S., \& Woloshin, S. (2011). Overdiagnosed: Making People Sick in the Pursuit of Health. Boston, MA: Beacon Press. 